\title{
Precise Lighting for Shade Matching
}

Ravichandran Varsha ${ }^{1}$, Shivasakthy Manivasakan², David W Livingstone ${ }^{3}$, Albert Jenie Rosna ${ }^{4}$

Journal of Scientific Dentistry (2019): 10.5005/jp-journals-10083-0911

\section{INTRODUCTION}

A rite-lite 2-shade matching unit with $\mathrm{HI}-\mathrm{CRI}$ (high color rendering index) LEDs is used to reproduce the visual spectrum as produced by natural sunlight. The diffused LED technology in this device aids in matching the shade for teeth and dental restorations with the simulation of various lighting conditions.

\section{Three Modes Offered by the Rite Lite 2 Shade Matching Unit}

- Color-corrected light: 5,500 Kelvin (daylight)

- Incandescent, room light: 3,200 Kelvin (indoor environments)

- Ambient light: $3,900^{\circ}$ Kelvin (a combination of room light and daylight)

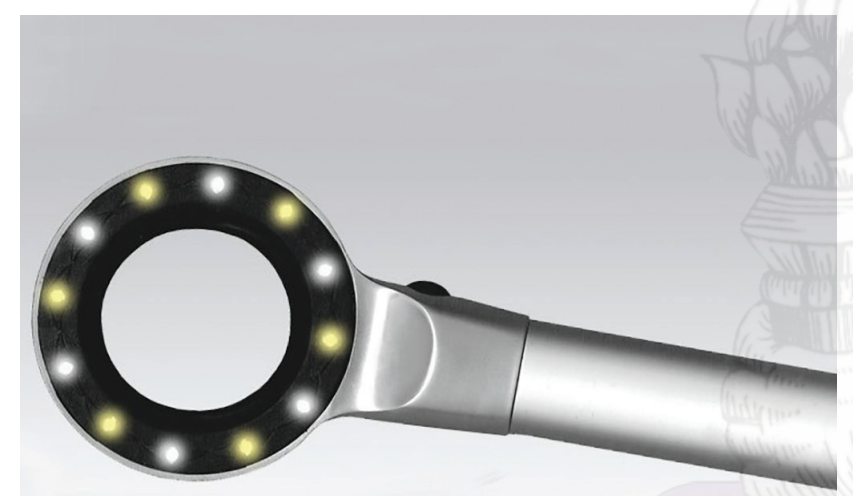

Fig. 1: Rite Lite 2 shade matching unit

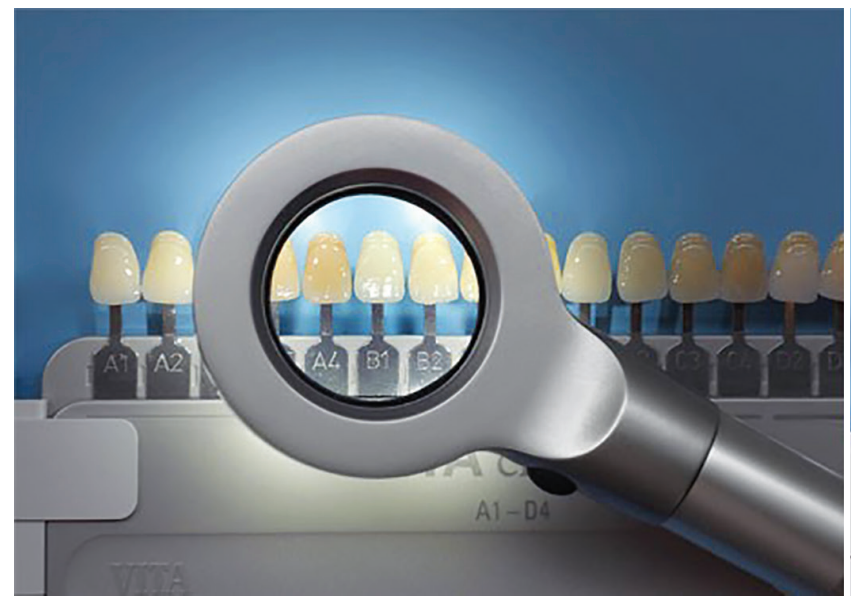

Fig. 3: Polarizing filter
${ }^{1}$ Department of Prosthodontics, Indira Gandhi Institute of Dental Sciences, Salem, Tamil Nadu, India

2,3 Department of Prosthodontics and Crown and Bridge, Indira Gandhi Institute of Dental Sciences, Sri Balaji Vidyapeeth (a Deemed University), Pillayarkuppam, Puducherry, India

${ }^{4}$ Department of Prosthodontics, Indira Gandhi institute of Dental Sciences, Madurai, Tamil Nadu, India

Corresponding Author: Ravichandran Varsha, Department of Prosthodontics, Indira Gandhi Institute of Dental Sciences, Salem, Tamil Nadu, India, Phone: +91 9047049915, e-mail: varsha95chandran@ gmail.com

How to cite this article: Varsha R, Manivasakan S, Livingstone DW, Rosna AJ. Precise Lighting for Shade Matching. J Sci Dent 2019;9(1):30-31.

Source of support: Nil

Conflict of interest: None

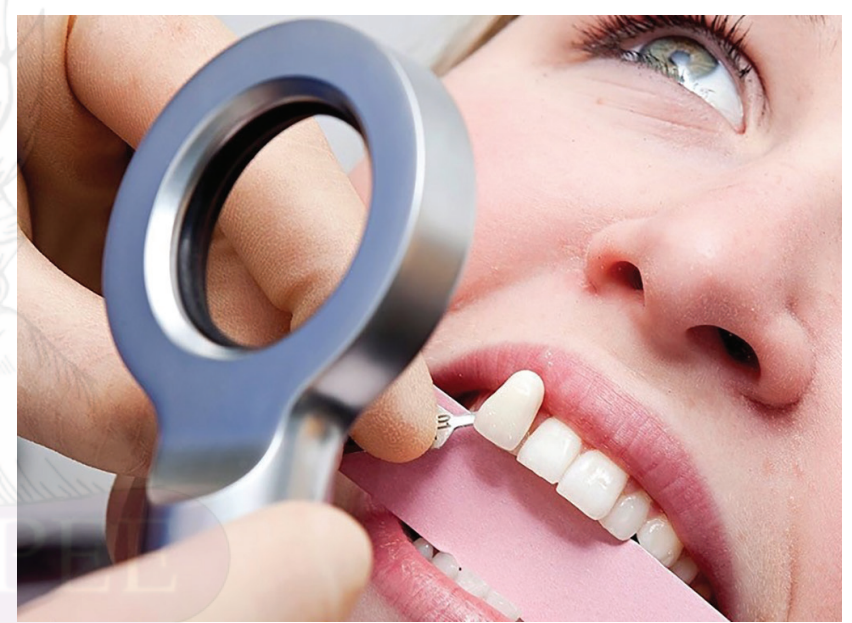

Fig. 2: Neutralizing colour tabs

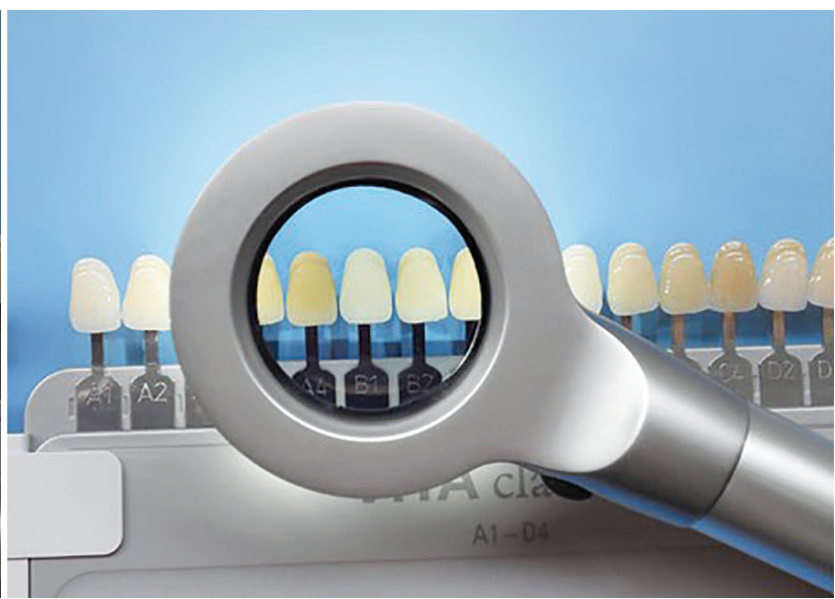

OThe Author(s). 2019 Open Access This article is distributed under the terms of the Creative Commons Attribution 4.0 International License (https://creativecommons. org/licenses/by-nc/4.0/), which permits unrestricted use, distribution, and non-commercial reproduction in any medium, provided you give appropriate credit to the original author(s) and the source, provide a link to the Creative Commons license, and indicate if changes were made. The Creative Commons Public Domain Dedication waiver (http://creativecommons.org/publicdomain/zero/1.0/) applies to the data made available in this article, unless otherwise stated. 


\section{FEATURES}

- Portability

- $5,500^{\circ}$ Kelvin, $3,200^{\circ}$ Kelvin, 3,900 Kelvin

- HI-CRI LED light source

- Simulates three lighting conditions from one source and standardizes lighting conditions between multiple locations

- Controlled viewing area

- Neutralizing color tabs are included

- Battery operated

- Voltage regulator

- Low battery indicator

\section{Benefits}

Rite Lite 2 (Fig. 1) offers the choice between three simulated lighting conditions (daylight, incandescent, and ambient light) and it is easy to toggle between the three lighting conditions with a one-touch control. It reduces glare and reflective highlights and eliminates shadowing from the upper lip; it distracts outside colour sources and colour distraction in oral cavity from interfering with shade selection. When neutralizing color tabs (Fig. 2) are placed behind the teeth, they eliminate colour distraction in the oral cavity. It is powered by two AA batteries and the LED provides 30,000 hours of life with a constant light output and a low battery indicator.

\section{Improved Built-in Feature}

This device has an accessory polarizing filter (Fig. 3) that can be attached. The polarizing filter is used to eliminate reflection and provides an enhanced visualization of tooth color, the internal details, individual characterization, and depth and transparency of the shade.

\section{Reference}

www.addent.com 